\title{
DireITo
}

\section{Novo Princípio da Eficiência Processual nas demandas individuais do Direito à saúde}

\author{
Marta Cristina Nunes Almeida ${ }^{1}$ \\ Jônatas Scheibe Meira ${ }^{2}$
}

\begin{abstract}
Resumo: A eficiência no processo judicial é fundamento inerente ao Poder Judiciário democrático e erigido conforme os ditames constitucionais, mormente quando o processo visa a resguardar direitos fundamentais urgentes, tal qual o Direito Social à saúde. Com o advento do princípio da eficiência processual no corpo do Novo Código de Processo Civil ${ }^{3}$ surgiu uma nova forma de disciplinar os conceitos fundamentais sobre a eficiência, no bojo de um processo judicial. A abordagem aqui proposta é analisar as implicações desse novo princípio na dinamização dos institutos e mecanismos processuais aplicados aos processos que resguardam o direito à saúde, com escopo de garantir o postulado da máxima efetividade dos direitos fundamentais.
\end{abstract}

Palavras-chave: Eficiência. Processual. Mecanismos. Direito à saúde.

Implications and implementation of the new Principle of the Procedural Efficiency in the demands that oversee the Right to Health

Abstract: The efficiency in the judicial procedure is a ground laying inherent to the democratic Judiciary and erected according to the constitutional dictates, especially when the process aims to protect urgent fundamental rights such as the Social Right to Health. With the advent of the principle of the procedural efficiency in the body of the New Code of Civil Procedure arised a new way of disciplining the fundamental concepts about efficiency in the bulge of a judicial procedure. The approach proposed here will be analyse the implications of this new principle in the dissemination of the institutes and the procedural mechanisms applied to the process that protects the right to health with the scope of ensuring the postulate of maximum effectiveness of the fundamental rights.

Keywords: Efficiency. Procedural. Mechanisms. Right to Health.

\footnotetext{
${ }^{1}$ Graduada na Universidade Católica de Salvador, pós-graduada em Direitos emergentes pela Universidade de Santa Catarina em convênio com a UESB, professora auxiliar de Processo Civil da Universidade Estadual do Sudoeste da Bahia (UESB). Defensora Pública Estadual da $2^{\circ}$ Regional Vitória da Conquista. E-mail: marta.almeida@defensoria.ba.def.br

${ }^{2}$ Acadêmico de Direito da Universidade Estadual do Sudoeste da Bahia (UESB). Estagiário Nível Superior da $2^{\circ}$ Regional da Defensoria Pública da Bahia. E-mail: jonatas.scheibe@gmail.com

${ }^{3}$ O Novo Código de Processo Civil refere à Lei n¹3.105/2015, no presente artigo será abreviado pela sigla "CPC/2015".
} 


\section{Introdução}

Embora insculpido no art. 196 da Constituição da República Federativa do Brasil de 1988 e sistematizada pela Lei 8.080/90, a proteção e promoção à saúde, como previsão Constitucional e infraconstitucional, não é suficiente pra realizar o direito fundamental à saúde de forma concreta.

Isso se deve ao fato que garantir a realização do direito fundamental à saúde exige uma prestação positiva por parte do Estado, pressupondo grandes disponibilidades de dinheiro dos cofres públicos. Eis o primeiro sustentáculo para a síndrome da inefetividade do direito à saúde, pelo qual foram criados diversos argumentos políticos-jurídicos, a exemplo do conhecido dogma da reserva do possível, como indubitável óbice econômico para a eficiência dos direitos fundamentais.

Devido ao abismo entre o discurso que afirma o direito fundamental à saúde, e seu cumprimento efetivo, nasceu o fenômeno da judicialização da política, mormente sobre a judicialização da saúde ${ }^{4}$, que é mais bem aprofundado no segundo capítulo do presente artigo. Tal fenômeno se deve principalmente pelo fato de que a Constituição brasileira é uma carta aberta de interpretações múltiplas, que chancela a atuação do Poder Judiciário na defesa dos direitos nela inseridos.

Logo, diante de manifesta inefetividade preexistente, a eficiência processual incide nas prestações judiciais com o fim de apaziguar, remediar e reverter a situação patológica que reside na efetivação da saúde individual e coletiva. O terceiro capítulo do presente artigo reserva-se nos estudos da definição e do alcance do princípio da eficiência processual nas prestações judiciais sanitárias.

Ocorre que tal princípio possui incidência interpretativa laborando como arquiteto de regras processuais nos atos e procedimentos de um processo judicial, in casu, que tutelem o Direito Social Fundamental à saúde.

No quarto capítulo do presente artigo será feita a análise do quadro crítico da efetivação do Direito à saúde pela via da judicialização, propondo o estudo dos mecanismos processuais inseridos no CPC/2015, aptos a concretizarem o princípio da eficiência processual, tais como: as prerrogativas da Fazenda Pública em Juízo, nova disciplina da tutela provisória, a institucionalização da tutela de evidência e sua aplicação prática e a recepção da estabilização da tutela antecedente pelo novo sistema processual.

\section{A judicialização da Saúde: a saga para exigir a promessa constitucional.}

A judicialização do direito à saúde vem pautado no macroprincípio da inafastabilidade do Poder Judiciário, pelo qual não se afastará da apreciação judicial lesão ou ameaça a lesão à direito constante no ordenamento jurídico, cujo normativo é o disposto no art. $5^{\circ}$, inciso XXXV da Constituição Federal de 1988:

Art. $5^{\circ}, \mathrm{XXXV:} \mathrm{"a} \mathrm{lei} \mathrm{não} \mathrm{excluirá} \mathrm{da} \mathrm{apreciação} \mathrm{do} \mathrm{Poder} \mathrm{Judiciário} \mathrm{lesão} \mathrm{ou} \mathrm{ameaça}$ a direito".

Devido à inserção dos direitos fundamentais como abstrações nos textos legais ou para serem aplicados em situações excepcionais, iniciou-se um processo de reconhecimento dos direitos individuais e sua correspondente capacidade processual denominada de Revolução Copernicana ${ }^{5}$, pelo qual se encerra o fenômeno do "ativismo judicial” ou "judicialização da política".

\footnotetext{
${ }^{4}$ Para um melhor aprofundamento, ver: Bezerra (2007).

${ }^{5}$ Sobre esse conceito, ver: Streck (2004).
} 
Outro fator para a crescente judicialização das demandas sanitárias é a textura aberta de nossa Constituição Federal, de modo que quanto mais indeterminada for a Constituição, maiores serão os conflitos pela interpretação hegemônica e maior será a discricionariedade do Poder Judiciário.

O ano de 1996 foi um marco na judicialização da saúde, porque o entendimento de que o direito fundamental à saúde era norma programática destituída de imperatividade levou ao indeferimento sumário de diversas ações individuais propostas no período. Logo após houve uma guinada jurisprudencial que se deu pela estruturação de programas e leis definindo o direito previsto no art. $6^{\circ}$ da Constituição Federal tal como a lei 8.080/90, como direito subjetivo, apto à judicialização pela via individual (MACHADO; DAIN, 2012, p. 468).

Tal cenário resultou no processo de judicializações que ocorreriam nos anos subsequentes, o que levou o Supremo Tribunal Federal a realizar a Audiência Pública sobre saúde entre abril e maio de 2009 e a proferir aspectos processuais importantes na apreciação da Suspensão de Tutelas Antecipadas no 175 e 278 (STA-AgRg/29/04/2010). Nesse período foram estabelecidos fundamentos importantes na judicialização da saúde como a responsabilidade solidária dos entes políticos e a titularidade coletiva e individual do direito à saúde, bem como foi consolidada a possibilidade de garantia e concretização do direito à saúde por meio da atuação do Poder Judiciário.

2.1 Críticas à judicialização: reconhecimento de desigualdades no acesso à justiça e de distribuição de recursos públicos

Em que pese a viabilidade no ajuizamento de ações que tutelem o direito à saúde, tal fenômeno não está livre de críticas pela doutrina especializada. A primeira grande crítica está na restrição oriunda da falta de acesso à justiça pelos jurisdicionados; nesse sentido Ingo Sarlet leciona :

[...] De outra parte, resulta no mínimo curioso o argumento de que a falta de isonomia quanto ao acesso à justiça, seja no que diz respeito à justiça, seja no que diz respeito à distribuição desigual em termos de assistência judiciária (incluindo a estruturação dos órgãos da Defensoria Pública, que, em virtude de limitações materiais, sequer está devidamente implantada em muitos lugares), seja no que concerne ao nível de informação do cidadão no que tange aos seus direitos, acaba gerando uma espécie de casta de privilegiados, que, em detrimento de expressivos segmentos da população, utilizam a via judicial para obtenção de prestações sociais (SARLET, 2012, p. 111).

Dessa forma, se cria mais um viés de acesso à saúde, ao ponto que a efetivação do direito à saúde fica restringida ao ajuizamento de uma ação judicial.

As críticas permanecem também com relação à alocação de recursos para a satisfação de direitos de alguns jurisdicionados em detrimento de outros membros da coletividade, favorecendo determinada camada social e gerando escassez de recursos sanitários na prestação da saúde por parte do Estado.

Não obstante o esforço dos argumentos desfavoráveis à judicialização da saúde, ressalta-se que, conforme mencionado, o Poder Judiciário é inafastável da apreciação das lesões a direito formalmente reconhecidos. Portanto, perfeitamente cabível a garantia da saúde por meio judicial-processual, sob pena de reduzir a ampla efetividade do acesso à saúde. 
2.2 A Fazenda Pública em juízo: confronto com a supremacia do interesse público

Nas ações de obrigação de fazer, de não fazer e de dar coisa certa no âmbito da saúde, o polo passivo da demanda é comumente ocupado pela Fazenda Pública.

O princípio da indisponibilidade do interesse público e a supremacia do interesse público norteiam o direito público e consequentemente a Fazenda pública. O Estado, por meio da administração pública, age segundo os ditames da legalidade estrita e ao se relacionar com os particulares, devem ser levadas em conta algumas prerrogativas inerentes à Fazenda Pública, com vistas a consagrar o princípio da Isonomia, no seu viés substancial ou material. As 'vantagens' processuais conferidas à Fazenda Pública revestem o matiz de prerrogativas, eis que contém fundamento razoável, atendendo, efetivamente, ao princípio da igualdade, no sentido aristotélico de tratar os iguais de forma igual e os desiguais de forma desigual (CUNHA, 2012a, p. 16).

Muito embora a legitimidade das prerrogativas da Fazenda seja latente, tais prerrogativas jamais podem obstar o devido processo legal e o processo judicial eficiente como imperativo do princípio da eficiência processual.

De nada adianta agir com zelo excessivo para com o Poder público se o direito fundamental à saúde não estiver atingindo a sua máxima efetividade. De igual modo, as prerrogativas da Fazenda não podem exercer tal importância, ao ponto de impedir um procedimento judicial eficaz, efetivo e eficiente.

\section{O princípio da eficiência processual no Novo Código de Processo Civil: a otimização da qualidade na gestão do processo}

De imediato, cabe a distinção entre o princípio Constitucional da eficiência insculpido no art. 37, caput, da Constituição Federal de 1988, e o princípio da eficiência processual que aduz o art. $8^{\circ}$ do CPC/2015.

A eficiência que atinge a administração pública na seara do Poder Executivo busca evitar a impotência estatal na luta contra a deficiente prestação de serviços públicos e na execução da atividade administrativa típica do Estado. São as lições de José dos Santos Carvalho Filho, in verbis:

O núcleo do princípio é a procura de produtividade e economicidade e, o que é mais importante, a exigência de reduzir os desperdícios de dinheiro público, o que impõe a execução de serviços públicos com presteza, perfeição e rendimento funcional. Há vários aspectos a serem considerados dentro do princípio, como a produtividade e economicidade, qualidade, celeridade e presteza e desburocratização e flexibilização (CARVALHO FILHO, 2013, p. 30).

Por sua vez, o princípio da eficiência insculpido no artigo $8^{\circ}$ do CPC/2015 tem enfoque na gestão do processo judicial, seus atos e procedimentos, objetivando a melhor decisão na macrojustiça. Vale a citação do professor Humberto Theodoro Jr., ao lecionar sobre a essência do princípio da eficiência processual:

O princípio da eficiência deve ser analisado, principalmente, sob o enfoque qualitativo, i.e, levando-se em conta a qualidade e a adequação da prestação jurisdicional entregue ás partes. O litígio deve ser decidido pelo juiz de forma completa, abrangente, ainda 
que esta atividade demande maior dispêndio de tempo. Entre a rapidez da decisão e a qualidade da decisão e a qualidade da solução apresentada, o juiz deve primar pela segunda, de modo que nunca seja ela sacrificada em prol apenas da dinamicidade do processo (THEODORO JR., 2016, p. 93).

A inserção do art. $8^{\circ}$ do CPC/2015 leva à reflexão sobre o mandamento principiológico a partir da ótica de pressuposto normativo fundamental e que sua incidência deve ocorrer na utilização de cada instituto que acompanha o CPC, sob pena de retirar o significado imanente em todo o corpo do codicium.

Dessa forma, o princípio da eficiência deve ser levado a sério como norte interpretativo dos demais princípios do processo, e sua releitura deve sempre retomar ao conteúdo normativo constitucional, exposto no art. 37, caput, da Constituição Federal

3.1 O estudo do Princípio e sua estruturação no Novo Código de Processo Civil: postulado hermenêutico contemporâneo

Os princípios, de maneira geral, se diferem das regras em razão de não serem postulados determinantes para uma decisão, apresentando mais de uma solução argumentativa, quando analisada à luz de uma posição jurídica. No entanto, essa conclusão não surgiu assim tão facilmente exigindo um esforço doutrinário na evolução do conceito e limitação dos princípios.

A solução na colisão principiológica ao fato concreto, por exemplo, não vinha arraigada de conceitos como a dimensão do peso elencado por Alexy (2015, p. 54) e tampouco se falava em proporcionalidade na aplicação das normas principiológicas, vez que o sistema do all or nothing fashion ${ }^{6}$ corrente na aplicação das regras jurídicas, era proeminente no positivismo jurídico.

O Brasil adotou a teoria da normatividade dos princípios com o advento da Constituição Federal de 1988, e o CPC/2015 evidencia esta forte tendência, visto que é visivelmente claro o estabelecimento de princípios fundamentais do processo como premissas interpretativas nos primeiros artigos do Código Adjetivo, mais precisamente entre o artigo $1^{\circ}$ e 12 da compilação processual.

Tais princípios devem ser somados às novas regras instituídas, determinando uma releitura do processo a partir do processamento constitucionalmente democrático e justo. Porém, antes de adentrar no estudo do princípio da eficiência e sua estruturação no CPC/2015, é por demais válido o entendimento do avanço da doutrina principiológica na ciência jurídica.

A consolidação da tradição do positivismo jurídico no final do século XIX demonstrou que a norma jurídica em sua abstratividade e imperatividade, não alcançaria a complexidade dos fatos jurídicos e das posições sociais que se criam e se desfazem no seio do convívio social. Ante isto, a mera subsunção do fato à norma ou da norma ao fato demonstrou-se incapaz de garantir a aplicação efetiva do ordenamento jurídico aos jurisdicionados.

Nesse contexto e diante da existência de lacunas (anomias) no Direito, vem à existência os chamados Princípios Gerais do Direito, figurando como elementos supletivos à disposição do aplicador da lei. Salienta-se que a ideia de princípios gerais de direito tem muito pouco a ver com o sentido de princípio atual assumido após o positivismo jurídico e o neoconstitucionalismo. O juiz atual não pode se assemelhar com o juiz idealizado por Kelsen, como sendo aquele que partia de um apanhado de regras e leis, extraindo o sentido intrínseco da lei e aplicando ao caso concreto.

"Aplicação "tudo ou nada", comum no sistema de regras do Positivismo Jurídico. 
A proposta de Hans Kelsen não previa que da atividade intelectual de extrair a norma da lei por intermédio da busca do sentido desta pelo magistrado, criava uma postura decisionista, acarretando sérios efeitos na justiça das decisões.

Nesse ínterim, se fez necessário a atribuição de força normativa aos princípios. Logo, não mais existiriam apenas normas-regras regendo o ordenamento jurídico, mas também a insurgência das normas-princípios que, antes de tudo, permaneciam com o conteúdo de normas em sua abstratividade, generalidade, imperatividade, bilateralidade e coercibilidade.

A dignidade normativa dos princípios se intensificou com os estudos propostos por Dworkin e Robert Alexy. O primeiro, em seus estudos, realizou a importante distinção entre princípios e diretrizes políticas, retomando, então, a relação entre princípios e diretrizes políticas, podese afirmar que um princípio prescreve um direito e, por isso, contém uma exigência de justiça, equanimidade ou devido processo legal; ao passo que uma diretriz política estabelece um objetivo ou uma meta a ser alcançado, que, geralmente, consiste na melhoria de algum aspecto econômico, político ou social da comunidade, buscando promover ou assegurar uma situação econômica, política ou social considerada desejável. Dworkin atribui o status de trunfos aos princípios, que, em uma discussão, devem se sobrepor a argumentos pautados em diretrizes políticas, excluindo a possibilidade de os juízes tomarem decisões embasadas nessas diretrizes (THEODORO JR. et al., 2015, p. 52-53).

Partindo da visão defendida por Dworkin, e consoante já mencionado, o princípio da eficiência deve se sobrepor aos argumentos pautados em diretrizes políticas. Ora, posto isto, constata-se que o instituto da reserva do possível é um manifesto argumento utilizado pelos Tribunais pautado em diretrizes políticas, econômicas e sociais. Assim sendo, a guisa de exemplificação, jamais poderse-ia afastar a incidência da máxima eficiência em um processo que tutele medicamentos juntos à Fazenda Pública, somente com base na reserva do possível pela insuficiência de recursos dos cofres públicos. Tal raciocínio advém da dogmática dos princípios que sempre devem se sobrepor às diretrizes políticas.

Tamanha é a importância do tema sobre os efeitos da eficiente aplicação dos direitos fundamentais, que levou Alexy a lecionar a respeito da relevância do enquadramento dos princípios para racionalização dos direitos fundamentais, ipsis litteris:

Essa distinção é a base da teoria da fundamentação no âmbito dos direitos fundamentais e uma chave para a solução de problemas centrais da dogmática dos direitos fundamentais.

$[\ldots]$

A distinção entre regras e princípios constitui, além disso, a estrutura de uma teoria normativa-material dos direitos fundamentais e, com isso, um ponto de partida para a resposta à pergunta acerca da possibilidade e dos limites da racionalidade no âmbito dos direitos fundamentais (ALEXY, 2015, p. 85).

Sobre essa ótica, encontra-se o sentido pós-positivista da teoria normativa dos princípios. No entanto, cabe ainda apontar as precisas lições de Robert Alexy quanto ao valor axiológico dos princípios e a sua natureza de mandamentos de otimização.

No que tange à dimensão de peso do princípio, tem-se que na colisão de princípios se destacará aquele que o valor decisório para o caso concreto for o de maior peso. Princípios são, por conseguinte, 
mandamentos de otimização, que são caracterizados por poderem ser satisfeitos em graus variados e pelo fato de que a medida devida de sua satisfação não depende somente das possibilidades fáticas, mas também, das possibilidades jurídicas. O âmbito das possibilidades jurídicas é determinado pelos princípios e regras colidentes (ALEXY, 2015, p. 90). Tal quadro faz surgir a seguinte indagação: qual o valor/peso do princípio da eficiência processual insculpido no artigo $8^{\circ}$ do CPC/2015? E a sua otimização no caso concreto?

De imediato, informa-se que a resposta de tal questionamento consiste em enxergar a eficiência sob a ótica de pressuposto normativo fundamental do CPC/2015. Nesse sentido, Humberto Theodoro Jr. afiança:

Começando do art. $8^{\circ}$, este assenta a premissa de que a atividade judicante- antes de tudo- deve se fixar ao atendimento de pressupostos normativos fundamentais, que nortearão sua dinâmica:

Art. $8^{\circ}$ Ao aplicar o ordenamento jurídico, o juiz atenderá aos fins sociais e às exigências do bem comum, resguardando e promovendo a dignidade da pessoa humana e observando a proporcionalidade, a razoabilidade, a legalidade, a publicidade e a eficiência.

Do texto, portanto, se identifica que a "metodologia da proporcionalidade" será empregada pelo Judiciário nos casos de aplicação de princípios (THEODORO JR. et al., 2015, p. 40).

Tal metodologia da proporcionalidade indicada pelo autor é aquela que toma por base três sub-regras: a adequação, a necessidade, e a proporcionalidade em sentido estrito. Logo, incidirá com preponderância o princípio mais adequado ao caso, e, em segundo momento, estabelece-se a necessidade da medida judicial, para, finalmente, promover-se o teste da proporcionalidade em sentido estrito. Prossegue Alexy (2015, p. 118), afiançando com propriedade que, "A máxima da proporcionalidade em sentido estrito decorre do fato de princípios serem mandamentos de otimização em face das possibilidades jurídicas".

No bojo de uma ação judicial, o princípio da eficiência como pressuposto normativo fundamental deve surgir como de alto nível axiológico; assim, deve ser utilizado como mandamento de otimização e por ser princípio e não uma diretriz deve sobrepor aos argumentos pautados em diretrizes políticas, tal como a reserva do possível ou a reserva dos cofres públicos.

Por fim, cabe mencionar a definição dos professores Marinoni, Arenhart, Mitidiero sobre o conteúdo do princípio da eficiência processual, no bojo da tutela de direitos individuais e coletivos, in verbis:

O juiz deve dirigir o processo de modo eficiente. Isso significa que deve alocar tempo adequado e dimensionar adequadamente os custos da solução de cada litígio. A necessidade de eficiência na gestão do processo guarda íntima relação com a ideia de proporcionalidade entre os meios e os fins que são visados pela administração da Justiça Civil (MARINONI; ARENHART; MITIDIERO, 2015, p. 107).

\section{Medidas processuais que concretizam a eficiência nas demandas de saúde: tutelas provisórias}

A eficiência como pressuposto normativo fundamental do Novo Código Adjetivo, exige a sua concretização em respeito à metodologia da proporcionalidade defendida por Robert Alexy 
(2015). Deve-se evitar que o Princípio da Eficiência Processual seja eivado da inefetividade epistêmica, típica do panprincipiologismo que assola a concretização dos princípios pelo Poder Judiciário brasileiro.

Para tanto, a eficiência deve ser aplicada nos instrumentos processuais inseridos no CPC/2015; de tal modo, a título de exemplo, assegura-se que a boa utilização da tutela de evidência e do poder de efetivação, por si só, concretizariam a eficiência substanciada no princípio processual em comento.

A seguir, urge como essencial uma análise dos institutos que foram reformados e inovados pelo CPC/2015, aptos a concretizarem o princípio da eficiência processual no âmbito das demandas que pleiteiam direito à saúde. É salutar registrar, de pronto, que os aludidos Institutos estão presentes em quase toda a totalidade de ações ajuizadas no âmbito da efetivação da saúde, notadamente naquelas ações que pleiteiam obrigações de fazer, de não fazer e de dar coisa certa por parte da Fazenda Pública.

4.1 A estabilização da tutela de urgência satisfativa antecedente: autonomização da decisão provisória

Surge no Novo Código de Processo Civil, na Lei no 13.105/2015, o instituto da estabilização da tutela de urgência satisfativa antecedente, apta a concretizar o princípio da eficiência processual no bojo das demandas de saúde.

Tal fenômeno advém da técnica "Référé" (DIDIER, 2015, p. 605), do Direito Francês, que permite a desvinculação da cognição sumária da cognição exauriente, também conhecida como autonomização ou estabilização da tutela sumária. Assim dispõe o art. 304 do CPC:

Art. 304. A tutela antecipada, concedida nos termos do art. 303, torna-se estável se da decisão que a conceder não for interposto o respectivo recurso.

$\int 1^{\circ}$ No caso previsto no caput, o processo será extinto.

Tal normatização admite que os efeitos da tutela satisfativa perdurem mesmo com a extinção do processo, desde que o requerente explicite sua vontade pela estabilização da demanda (art. 303, $\$^{\circ}$ ) (THEODORO JR., 2015, p. 681).

No Direito Francês e Italiano foi criado essa autonomização com base nas pesquisas conclusivas de que a maioria das decisões concedidas em sede de tutela antecipada era confirmada na decisão definitiva.

No Brasil a adoção de tal instituto, não foi por outro motivo. Em pesquisa realizada pelo CNJ (2015) constatou-se que na maioria dos casos de saúde sub judice houve deferimento do pedido de antecipação da tutela sem pedido de informações complementares. Além disso, na maioria dos casos houve confirmação do deferimento do pedido na sentença de $1^{\circ}$ grau e no acórdão de $2^{\circ}$ grau.

Logo, sua utilização na prática pode gerar a melhor e mais célere cristalização de direitos, além de resultar maior economia processual nas demandas sanitárias.

Esta estabilização ocorre somente quando ela é concedida em caráter antecedente e não é impugnada pelo réu, litisconsorte ou assistente simples, seja por recurso ou por outro meio de impugnação. Não ocorrendo impugnação, o processo será extinto e a decisão antecipatória continuará produzindo efeitos, enquanto não for ajuizada ação autônoma para revisá-la, reformá-la ou invalidála (DIDIER, 2015, p. 604). 
Há que ressaltar que a estabilização não gera resolução do mérito quanto ao pedido final, apenas a propagação dos efeitos da decisão. Com isso, a decisão proferida por meio de antecipação de tutela pode produzir efeitos sem depender de instauração do processo de conhecimento de cognição plena, e a faculdade de rediscutir o direito material respeita o prazo decadencial de dois anos, contado da ciência da decisão que extinguiu o mérito.

Ora, tal propagação dos efeitos da decisão, somada à economia processual e à celeridade, sobretudo na garantia de direito urgente à saúde, pode modificar a ótica da própria Fazenda em relação ao interesse na impugnação da decisão que estabilizou a demanda. No entanto, o comportamento da Fazenda Pública só será construído no decorrer das práticas processuais e na utilização do inovador instituto da estabilização.

4.2 A tutela de Evidência e as restrições de liminares contra a Fazenda Pública: uma possibilidade de superação

A tutela de evidência é espécie de tutela provisória sem o requisito da urgência e sempre tem caráter satisfativo e seu procedimento não prevê a tutela antecedente. É pautada na pretensão fundada em comprovação suficiente do direito material, capaz de ensejar certeza e evidência do direito. A sede da tutela de evidência vem prevista no art. 311 do CPC/2015, in verbis:

Art. 311. A tutela da evidência será concedida, independentemente da demonstração de perigo de dano ou de risco ao resultado útil do processo, quando:

I - ficar caracterizado o abuso do direito de defesa ou o manifesto propósito protelatório da parte;

II - as alegações de fato puderem ser comprovadas apenas documentalmente e houver tese firmada em julgamento de casos repetitivos ou em súmula vinculante;

III - se tratar de pedido reipersecutório fundado em prova documental adequada do contrato de depósito, caso em que será decretada a ordem de entrega do objeto custodiado, sob cominação de multa;

IV - a petição inicial for instruída com prova documental suficiente dos fatos constitutivos do direito do autor, a que o réu não oponha prova capaz de gerar dúvida razoável.

Parágrafo único. Nas hipóteses dos incisos II e III, o juiz poderá decidir liminarmente.

Desta forma, observa-se que a tutela poderá ser deferida tanto liminarmente quanto incidentalmente. As hipóteses do inciso I, II e IV podem gerar efeitos nas demandas de saúde desde que bem fundamentadas em provas documentais e, no caso do inciso II, estejam pautadas em tese firmada em julgamento de casos repetitivos ou em súmula vinculante.

Importante observar que a doutrina entende que as restrições mencionadas à tutela de urgência não se aplicam à tutela de evidência, o que gera mais um mecanismo processual na consagração do princípio da eficiência processual. Nesse sentido, Marinoni, Arenhart, Mitidiero lecionam sobre a tutela de evidência e a restrição ao esgotamento, no todo ou em parte, do objeto da ação, ipsis litteris:

Logicamente, a restrição de concessão de liminar que esgote, no todo ou em parte, o objeto da ação (art.1 $1^{\circ}, \$ 3^{\circ}$, Lei 8.437/92) não se aplica nos casos de tutela de evidência (art. 311, CPC) Ademais, no entendimento do Supremo Tribunal Federal, a proibição 
de esgotamento do objeto da ação deve relacionar-se às hipóteses em que é proibida a concessão de medida liminar (MARINONI; ARENHART; MITIDIERO, 2015, p. 996).

Outro entendimento é que o Poder Público, assim como qualquer parte processual, tem o dever de respeitar os precedentes judiciais e os casos em julgamento repetitivos, não havendo que se falar em restrição como uma exceção ao cumprimento dos provimentos vinculantes.

De igual modo, seria absurdo não aplicar a tutela de evidência quando "evidenciado o abuso de defesa ou o manifesto propósito protelatório da parte" (art. 311, I). Ainda, somados a esse fato, tem-se o enunciado n. 34 do Fórum Permanente de Processualistas Civis:

Considera-se abusiva a defesa da Administração Pública, sempre que contrariar entendimento coincidente com orientação vinculante firmada no âmbito administrativo do próprio ente público, consolidada em manifestação, parecer ou súmula administrativa, salvo se demonstrar a existência de distinção ou da necessidade de superação do entendimento (DIDIER, 2015, p. 635).

A posição mais coerente e que melhor concretiza o princípio da eficiência processual é pela não aplicação das restrições à tutela de urgência em sede de tutela de evidência. Tal entendimento, doutrinariamente majoritário, evitaria, por exemplo, o abuso de defesa e os atos protelatórios por parte da Fazenda Pública, além de reforçar o sistema de provimentos vinculantes e, consequentemente, o princípio da eficiência processual no viés do contraditório efetivo.

4.3 O Poder Geral de Efetivação e as medidas adequadas para a garantia dos efeitos antecipáveis

A grande razão de ser da tutela provisória é conferir efetividade à função jurisdicional, de modo que somente quando a medida for apta a alcançar a efetividade, é que deverá ser concedida.

Logo, nada adianta a concessão dos efeitos antecipáveis na tutela provisória se o juiz não lançar mão de medidas adequadas para a efetivação e cumprimento da decisão. A essa série de medidas adequadas para a efetivação da demanda dá-se o nome de poder geral de cautela e de efetivação.

Há que mencionar que o juiz não pode conceder a tutela provisória ex officio, se tal medida pode ser garantida pelo poder de efetivação, fundamentado no princípio da eficiência processual.

A efetivação encontra sede no regramento previsto no art. 297 do CPC/2015:

Art. 297. O juiz poderá determinar as medidas que considerar adequadas para efetivação da tutela provisória.

Theodoro Jr. (2016, p. 640) denomina de poder geral de prevenção, previsto nos arts. 297 a 301 do CPC/2015, a prevenção que se destina apenas aos casos em que alguma medida provisória for necessária para coibir risco de injustiça ou de lesão, que ameace o direito de uma das partes, antes do julgamento de mérito ou da solução do processo, comprometendo a efetividade da tutela jurisdicional.

Dessa forma, o juiz pode se valer de medidas nominadas e inominadas para a asseguração do direito, desde que as medidas sejam adequadas para tanto (art. 301 do CPC/2015). Daí nasce 
uma questão importante sobre a adequação da medida, uma vez que muito embora o juiz tenha discricionariedade, deve observar a razoabilidade e a proporcionalidade na escolha de tais medidas, uma vez que o Código exige a escolha da medida "adequada". Nesse sentido, Theodoro Júnior. sustenta:

[...] O juiz, no processo, nunca pode deixar de praticar o ato necessário, segundo a regra legal. A conveniência e oportunidade decorrem da própria vontade da lei. Ao juiz cabe apenas a liberdade restrita de traçar-lhe o conteúdo prático (THEODORO JR, 2016, p. 640).

Logo, tal instituto guarda íntima correlação com a eficiência processual, de modo que quanto mais justa for a aplicação do poder geral de efetivação, mais concretude se dá ao princípio em comento. Isto porque, os postulados de adequação, necessidade e proporcionalidade em sentido estrito estruturam ambos os institutos que devem ser analisados sob a ótica do processo democratizado.

Tal amplitude do poder geral de cautela, prevenção ou efetivação poderia acarretar o aumento dos chamados free riders, aqueles aventureiros processuais que ajuízam demandas sem a devida necessidade e urgência e sem a comprovação do direito apto a fundar uma cognição exauriente. Para tanto, foi reestruturado no Novo Código de Processo Civil, a responsabilização objetiva em desfavor de quem se valeu da medida provisória (art. 302, e incisos), com destaque para o inciso I, que traz a hipótese de sentença final desfavorável ao beneficiário da medida que não conseguiu comprovar o seu direito.

Prestadas essas informações, o Código remete a efetivação da tutela provisória ao regime legal de execução provisória (arts. 520 a 522). Mais detidamente nos casos do direito à saúde, a efetivação se dá pelo art. 536 do CPC/2015 (ulterior art. 461 do CPC/73), que trata do cumprimento de sentença que reconheça a exigibilidade de obrigação de fazer, de não fazer ou de entregar coisa.

A primeira das grandes medidas é a imposição da multa diária ou astreintes (art. 536, $₫ 1^{\circ}$ ), como meio indireto de coerção da Fazenda Pública no cumprimento das obrigações atinentes ao direito de saúde, tal como fornecimento de medicamentos e realização de transferência para UTI especializada, podendo ser imputado como responsável pela multa o agente público incumbido pelo cumprimento do ato, circunstância que gera maior objetividade na fixação das astreintes.

Cabem como medida de efetivação, a busca e a apreensão, a remoção de pessoas ou coisas, o desfazimento de obras e o impedimento de atividade nociva, podendo, em qualquer caso, a utilização de força policial.

Para garantir o resultado útil do processo, é comum o pedido de bloqueio de verbas públicas como meio coercitivo direto, buscando a satisfação do resultado equivalente à tutela provisória deferida, "resguardando, assim, não somente a efetividade da jurisdição, mas principalmente, regras e princípios constitucionais de maior prevalência axiológica, visando garantir a máxima efetividade possível ao texto constitucional e conferir harmonia ao texto constitucional" (BONFIM, 2014, p. 186).

A não observância da decisão pode gerar além das sanções processuais (art. 536, $₫ 3^{\circ}$ ), das perdas e danos, as sanções penais (arts. 319 e 330 do Código Penal), que podem acarretar a prisão em flagrante do agente que se nega a cumprir a medida judicial.

Em suma, o rol de medidas nominadas, somadas às medidas inominadas, acessíveis para assegurar o cumprimento das decisões, devem ser utilizadas adequadamente pelos julgadores, uma vez que a simples prolação de decisões interlocutórias antecipando os efeitos da sentença não 
tem o condão de gerar o efetivo gozo e fruição desse direito pelos jurisdicionados que pleiteiam medicamentos, cirurgias, transferências etc. Assim, o julgador que observa a normatividade do princípio da eficiência processual lança mão do poder geral de efetivação, para garantir cristalização do direito à saúde.

\section{Considerações conclusivas}

Em havendo uma verdadeira síndrome de inefetividade nas normas que tratam do direito fundamental à saúde, e, consequentemente, da própria prestação dos serviços relativos à saúde por parte do poder estatal, notadamente nas prestações ligadas ao sistema público de saúde (SUS), surge a necessidade de viabilizar o direito à saúde, por intermédio da atuação judicial.

O presente artigo objetivou a análise processual e prática do princípio da eficiência processual nas demandas que pleiteiam o direito à saúde, suas nuances, aplicação e concretização juntamente com as inovações inauguradas pelo CPC/2015.

Os mecanismos processuais apresentados tais como: a tutela provisória antecedente, implicações sobre a tutela de evidência, o poder geral de efetivação das decisões antecipáveis, são sim aptos para a concretização da eficiência processual nas demandas de saúde, viabilizando a máxima efetividade na prestação do direito social à saúde.

A dinamização dos institutos e mecanismos processuais aplicados aos processos que resguardam o direito à saúde com fulcro no princípio da eficiência processual, é trabalho árduo, porém, o resultado deste labor, indubitavelmente, consolidará um Judiciário instrutor de processos mais eficientes, democráticos e justos.

\section{Referências}

ALEXY, Robert. Teoria dos direitos fundamentais. 2. ed., $4^{a}$ tiragem. Trad. Virgílio Afonso da Silva. São Paulo: Malheiros, 2015.

BEZERRA, Paulo Cesar Santos. Temas atuais de direitos fundamentais. 2. ed. revisada e ampliada. Ilhéus-BA: Editus, 2007.

BONFIM, Ludio Rodrigues. A tutela antecipada e a efetivação do direito fundamental à saúde. Revista Jurídica da Defensoria Púbica da Babia, v. 1, Salvador, 2014. Edição temática: "tutela coletiva e individual de direitos".

CARVALHO FILHO, José dos Santos. Manual de Direito Administrativo. 26. ed. rev., ampl. e atual. São Paulo: Atlas, 2013.

CONSELHO NACIONAL DE JUSTIÇA (CNJ). Justiça Pesquisa: judicialização da saúde no Brasil, dados e experiências. Coordenadores: Felipe Dutra Asensi e Roseni Pinheiro. Brasília, 2015.

CUNHA, Leonardo Carneiro da. A Faz̧enda Pública em juízo. 10. ed. São Paulo: Dialética, 2012a.

A previsão do princípio da eficiência no projeto do novo Código de Processo Civil Brasileiro. Revista de Processo, São Paulo: RT, n. 233, 2012b. 
DIDIER, Fredie. Curso de Direito Processual Civil. Introdução ao direito processual civil. 17. ed. Salvador: Editora Juspodivm: 2015

MACHADO, Felipe Rangel de Souza, DAIN, Sulamis. Direito e saúde: contribuições para o estudo da judicialização de direito sanitário. In: ASENSI, Felipe; PINHEIRO, Roseni (Org.). Direito sanitário. Rio de Janeiro: Elsevier, 2012.

MARINONI, Luiz Guilherme; ARENHART, Sérgio Cruz; MITIDIERO, Daniel. Novo Código de Processo Civil comentado. São Paulo: Editora Revista dos Tribunais, 2015.

SARLET, Ingo Wolfgang. A titularidade simultaneamente individual e transindividual dos direitos sociais analisada à luz do exemplo do direito à proteção e promoção da saúde. In: ASENSI, Felipe; PINHEIRO, Roseni (Org.). Direito sanitário. Rio de Janeiro: Elsevier, 2012.

STRECK, Lênio Luiz. Jurisdição constitucional e hermenêtica constitucional. Porto Alegre: Livraria do Advogado, 2004.

THEODORO JR., Humberto. Curso de Direito Processual Civil - Teoria Geral do Direito Processual Civil, processo de conhecimento e procedimento comum. Edição rev., atual. e ampl. Rio de Janeiro: Forense, 2016. v. 1.

et al. Novo CPC - fundamentos e sistematização. 2. ed. rev. e ampl. Rio de Janeiro: Forense, 2015.

\section{Obras consultadas}

MARINONI, Luiz Guilherme. Precedentes obrigatórios. 3. ed. São Paulo: Editora Revista dos Tribunais, 2013a. $2013 b$.

Processo de conhecimento. 11. ed. rev. e atual. São Paulo: Editora Revista dos Tribunais,

SARLET, Ingo Wolfgang; FIGUEIREDO, Mariana Filchtiner. Notas sobre o direito fundamental à proteção e promoção da saúde na ordem jurídico-constitucional brasileira. In: ASENSI, Felipe; PINHEIRO, Roseni (Org.). Direito sanitário. Rio de Janeiro: Elsevier, 2012.

Algumas considerações em torno do conteúdo, eficácia e efetividade do direito à saúde na Constituição de 1988. RERE - Revista Eletrônica sobre a Reforma do Estado, Salvador, n. 11, set./nov. 2007. Disponível em: <http://www.egov.ufsc.br/portal/sites/default/files/rere-11setembro-2007-ingo_sarlet_1.pdf>. Acesso em: 22 maio 2016.

SARMENTO, Daniel; TELLES, Cristina. Judicialização da saúde e responsabilidade federativa: solidariedade ou subsidiariedade. In: ASENSI, Felipe; PINHEIRO, Roseni (Org.). Direito sanitário. Rio de Janeiro: Elsevier, 2012. 